$\underline{\text { Article }}$

\title{
Grand Challenges within IB: Conducting Qualitative Research in the Covid Environment
}

\author{
Amir Qamar' ${ }^{1}$ ', John Child' \\ 1 Birmingham Business School, University of Birmingham, UK \\ Keywords: research methods, covid-19, grand challenges, qualitative research, phenomenon-driven methodology \\ https://doi.org/10.46697/001c.25436
}

AIB Insights

Vol. 21, Issue 3, 2021

The new circumstances imposed by the Covid-19 pandemic create considerable uncertainty about the future nature of International Business (IB). This presents IB scholars with a 'grand challenge' of conducting research to inform theorizing about the new situation. Such research needs to be exploratory and highly sensitive to the nuances of new and evolving situations; in other words, qualitative and phenomenon-driven. We discuss the methodological implications of conducting qualitative research under the restrictions imposed by the pandemic and its aftermath. We argue that the IB discipline can use this disruption to remould traditional methodological practices and encourage technologically innovative methods.

\subsection{INTRODUCTION}

The Covid-19 pandemic has disrupted international trade, investment, and value chains, and led to significantly higher levels of political intervention (World Economic Forum, 2020). These developments present scholars with the 'grand challenge' (Buckley, Doh, \& Benischke, 2017) of understanding and theorizing about a new context of International Business (IB) that is complex, disruptive (Buckley, 2020) and uncertain (Sharma, Leung, Kingshott, Davcik, \& Cardinali, 2020). This calls for research that is exploratory and highly sensitive to the nuances of new and evolving situations, such as the role of MNEs in supporting local informal economies threatened by the social disruption of the Covid pandemic. It requires a method that is 'phenomenondriven', focused on capturing and conceptualizing new phenomena of interest. A phenomenon-driven approach aims to produce new knowledge about the unexpected (Huniche \& Sørensen, 2019). It is a method founded in observable phenomena that has 'the scholarly goal of building knowledge and developing ideas rather than a narrow focus on theory or data' (Schwarz \& Stensaker, 2016: 245-46). Such research is typically inductive and qualitative.

Grand societal challenges such as Covid-19 not only affect the society we study, but also how research is conducted. Qualitative research in IB has attracted methodological concerns in the past (Welch \& Piekkari, 2017) and now faces fresh challenges because of the new restrictions imposed by the Covid-19 pandemic. This is because the pandemic is challenging researchers to re-consider and adapt their designs, re-think their ethics, and broaden various avenues to access information. While higher education institutions have prioritised transitioning their infrastructure and modes of teaching in line with the new reality, there has as yet been only limited discussion concerning the transition of research methods. More specifically, we believe that limited training or guidance has been provided to staff and students on data collection, especially regarding qualitative data. This is particularly relevant when thinking about our pedagogic teaching resources. For instance, leading methodological textbooks have only limited content concerning contingency plans (i.e. overcoming grand challenges like Covid-19) and the use (and evaluation) of newer technologies and social media platforms with regard to the collection of data. Thus, the current situation provides new research opportunities (research on Covid-19 and its effects) as well as imposing new methodological constraints (research during Covid-19). In this article, we offer responsible guidance on the conduct of IB qualitative research in response to Covid-19. As Buckley et al. (2017) also suggest, we draw upon advances in the wider social sciences.

\subsection{QUALITATIVE RESEARCH IS NEEDED MORE THAN EVER BEFORE}

Not only will the pandemic have long-term repercussions within the global economy, but social distancing, quarantining and lockdowns will have a sizeable impact on teaching and research in the higher education environment. Arguably, the pandemic will particularly impact the social sciences because they study social behavior and relationships.

Although IB seeks to understand the evolving nature of 
businesses around the world, it must bear in mind that it is individuals and groups who make complex business decisions. Understanding businesses therefore requires an understanding of people. For example, what is the role of charismatic business leadership in energizing the extra-ordinary collective efforts required to overcome existential emergencies such as those induced by the pandemic and climate change? Qualitative inquiries that address individual sense-making and action offer the best method for capturing these social responses (Teti, Schatz, \& Liebenberg, 2020). Moreover, qualitative research is suited for inductive studies that surface new problems and phenomena in IB, such as those related to Covid-19. Although the statistical testing of IB hypotheses has certainly advanced, it has incurred criticism for relying on statistical rather than analytical significance, and more specifically for excessive quantification and testing of a niche set of IB theories (Delios, 2017). In turn, Collinson (2017) argued that the discipline is becoming collectively less relevant as applied research and "blue sky"/ theory-driven scholarship become more polarized. This polarization is between rigor and relevance. The need for relevance within a rapidly evolving environment underlies the case for more qualitative studies within IB as the discipline has become heavily reliant on quantitative research (Aguzzoli, Gardner, \& Newburry, 2021) and methodologically less diverse (Nielsen et al., 2020).

Given that people are social distancing and quarantining, responsible researchers must consider these factors when conducting their research projects. It is expected that quantitative researchers who make use of secondary datasets will be less impacted by Covid-related methodological constraints (Marhefka, Lockhart, \& Turner, 2020). By contrast, qualitative researchers will be disproportionally affected, given their traditional reliance on interaction with their participants in 'natural' field settings. This is a particular concern in view of the lack of qualitative research published within the discipline (Nielsen et al., 2020). With this in mind, we now offer guidance on how primary and secondary qualitative research can be conducted in the Covid environment.

\subsection{PRIMARY QUALITATIVE RESEARCH IN THE COVID ENVIRONMENT}

The pandemic has generated interesting new research issues that qualitative research is particularly suited to addressing. One example concerns changes in normative attitudes about working places and practices, including international business travel and meetings. However, we also need to think about how IB researchers can conduct such research under very different circumstances. Fortunately, qualitative researchers within the wider social sciences have started to outline some of the ways we can adapt our methodological practices during times of social distancing, lockdowns, remote working, and other restrictions. Although we are living in an unusual era, we can use this disruption to remould traditional, and sometimes too embedded, methodological practices, and encourage innovations in our field. Methodologically, we argue that grand challenges, like Covid-19, require phenomenon driven methodologies. The design of qualitative research essentially entails three different stages, namely: 1) site/industry selection and sampling; 2) data collection methods; and 3) data analysis strategies (Ravitch, 2020).

\subsection{SITE SELECTION AND SAMPLING}

Qualitative data collection is normally highly reliant on face-to-face interactions where data are acquired via interviews, focus groups and other forms of fieldwork (Ravitch, 2020). Yet, before reaching this stage, researchers can use online platforms to identify samples. Saunders, Lewis, \& Thornhill (2019) assert that quantitative research is reliant on large random samples, whereas qualitative studies are related with smaller, purposive (non-random) samples (for more information concerning qualitative sampling see Shaheen \& Pradhan, 2019). Over the last 15 years, social media have grown significantly and researchers can employ platforms (i.e. LinkedIn, Twitter, Facebook) as useful tools to identify and sample relevant businesses and individuals. With the new limitations on face-to-face interaction and networking, researchers may be apprehensive about how they can identify businesses and individual participants for their studies. They may also feel anxious when asking for people to give their time to be interviewed. This is not just a practical constraint, but also a crucial ethical consideration because the virus has led to many businesses reaching a tipping point in terms of their survival.

Many individuals are facing increased stress due to being unemployed or short on time, and in many circumstances, they are working from home trying to juggle family responsibilities. Although home working environments might also be regarded as a more relaxed and informal setting than a traditional office environment, Jowett (2020) advises that researchers must be responsible and sensitive to these pressures when approaching potential research participants. These considerations suggest that response rates and willingness to participate in research may be low, as many people now work from home. On the positive side, they may be willing to engage in interviews due to the human interaction they offer, which to some extent may compensate for the loss of a social work environment.

\subsection{DATA COLLECTION \& METHODS}

There is a range of technologies (Skype, Zoom, WhatsApp, etc.) which can be used to replace in-person encounters by virtual alternatives. Lobe, Morgan, \& Hoffman (2020) provide a detailed evaluation of these platforms when conducting video interviews. It is crucially important to recall that these approaches have their own limitations. For instance, some participants may not know how to use certain technologies, and poor internet connections (especially in emerging economies) may disturb the flow of interviews. Although phone-based interviews might be necessary in these kinds of situations, video interactions via technologies such as Skype or Zoom have the advantage that they can almost replicate the interaction a participant (and researcher) experiences during an in-person interview. This is because video interactions activate both auditory and visual senses, which potentially can generate greater levels of en- 
gagement (Marhefka et al., 2020). With regards to participant rapport and disclosure, Jenner \& Myers (2019) found that there is little difference between Skype and in-person interviews. Dodds \& Hess's (2020) thematic analysis of participant interviews and researcher reflections reveals benefits and limitations of online group interviews with vulnerable people. The benefits include being comfortable, non-intrusive and safe; engaging and convenient; the ease of online communication and set-up. The limitations relate to lack of non-verbal communication, poor set-up, and privacy and access issues.

Lobe et al. (2020) assert that most of the fundamental ethical issues in online interviewing are the same as in faceto-face contexts. They remind researchers to be responsible. Ethical issues should be kept in mind for all research and must not be overlooked in online research. In essence, video and phone calls are a substitute for face-to-face inperson interviewing, and they offer several benefits: there is no expenditure on travel, they offer a faster way of collecting data, and interviews can easily be conducted with respondents across the world without worrying about any pandemic-related restrictions. Methodological guidance is also now available on how best to conduct interviews in a virtual environment (Geisen, 2020; Jowett, 2020; Ravitch, 2020).

Ethnographic research usually involves the study of people and processes, and DeHart (2020) asserts that it may be possible to conduct it in times of restrictions as long as three factors are considered, namely: 1) what is under investigation; 2) where the study will take place; and 3) who is involved. Digital ethnography (also referred as Netnography) highlights a transition in focus away from human-objects and towards online sources. These online sources can be in the form of online documents, websites, blogs, and social media posts as a means of collecting information pertaining to attitudes, actions and behaviours (Mosca, 2014). Yet, forms of online social interaction online can be diverse and a key factor that researchers must consider when designing their research. For instance, one might conduct digital ethnographic research using social media whereas other researchers may use an online workplace space. Researchers must acknowledge that ethical considerations associated with traditional ethnographic research do not necessarily translate or apply to the digital environment. Markham (2003) assert that researchers need to curate a new approach to research ethics that reflects the new and digital environment. More information in some of the ways we can use secondary qualitative data is outlined in section 4.0.

\subsection{DATA ANALYSIS STRATEGIES}

Generally, the first step in qualitative data analysis is transcription (Bird, 2005), which is the conversion of audio files into textual data. This is considered to be highly valuable because researchers are reminded of intonations when speaking, laughs, sighs and other nonverbal sources of data. Denham \& Onwuegbuzie (2013) state that nonverbal data is already underutilized by researchers and is considered to be further jeopardised if interviews are conducted online. Moreover, software that converts speech to text has become increasingly common over the last 10 years and the shift to virtual interviewing could lead to a further decline in researchers transcribing their audio material. In turn, this can limit the familiarity that a qualitative researcher may develop with their data as they engage in a manual transcription process (Sinkovics, Penz, \& Ghauri, 2008). Yet, if interviews are recorded some of the missed/forgotten factors (i.e. nonverbal data) may be able to be picked up by the researcher during the transcription process, especially if the interviews are video recorded. Importantly, if researchers are analysing video files it is ethically imperative they take extra caution to maintain the anonymity of participants by reviewing the recorded files alone.

\subsection{SECONDARY QUALITATIVE RESEARCH IN THE COVID ENVIRONMENT}

The practices mentioned in section 3.0 relate to how researchers can adapt ongoing projects or make use of technology in research initiatives going forward in the Covid situation. Recent technological advances and social media platforms offer novel opportunities for both data collection and analysis that do not necessarily follow the traditional boundaries of qualitative vs quantitative research methodologies. For instance, secondary data of a qualitative nature can offer opportunities for theory development through inductive reasoning (Jamieson, 2020). Institutions often have access to qualitative data archives of research interviews and focus groups. These data are usually generated from peer-reviewed, funded, and published studies and have often already been anonymised and quality-assured, presenting opportunities for reanalysis and/or application. The analysis of archival data is particularly useful for postgraduate students who have a relatively short time in which to complete a dissertation.

Drawing on secondary qualitative data archives is less ethically risky than using primary sources and can increase the credibility of student outputs (Jowett, 2020). Yet, the use of deposited data is just one example of secondary qualitative research. One can also use print and broadcast media to analyse social representations of a wide range of topics. Some social scientists have also conducted secondary qualitative analysis of textbooks, websites, reports of inquiries, speeches, and debates. This has, for example, been the research strategy adopted by Andrew Brown in his studies of sensemaking (e.g. Brown, 2005), which we have previously suggested is a key subject for research aimed at understanding how companies are adjusting to the new unfamiliar environment. With regards to textual analysis, Jamieson (2020) recommends that researchers can follow four steps in utilizing archival and textual data: 1) research questions should be formulated that direct the enquiry towards the archived data sets; 2 ) with the assistance of computers, researchers should scrutinise the text (i.e. data mining - surface mapping concerning the breadth of the selected data sets); 3) the researcher should identify multiple relevant small samples which enact as 'test pits'; and 4) conduct an in-depth analysis of the selected sample. These data sources are not only readily available but also provide researchers with the opportunity to examine current and legitimate issues in society, as opposed to collecting specific 
data for the sole purpose of their - sometimes less relevant - research.

\subsection{CONCLUSION}

It is important that we do not isolate ourselves from the new realities presented by Covid-19 in the hope that things will return to a sense of normality in the near future. We must use this external shock to learn and innovate with regard to our methodological choices. It is vitally important that the IB discipline does not continue to publish largely quantitative research. Rather we should use the disruption to regain credibility for IB research both within the discipline and also amongst the growing number of qualitative social science researchers publishing in top-tiered journals. The grand challenge is not only to understand and theorize about the new context of international business created by the pandemic, but also to utilize a methodology whereby it can be understood as a social phenomenon.

At the same time, the pandemic has major implications for qualitative researchers who have to re-consider and adapt their designs, re-think their ethics and broaden various avenues to access information. Restrictions and social distancing mean that in-person fieldwork is most likely to be one of the last modes of research that will return to a state of normality (Wood, 2020). Technologies have revolutionised daily lives, and as this article demonstrates, they also provide opportunities to adapt extant data collection practices. The current situation is likely to encourage the adoption of more innovative approaches to doing research, including engaging in secondary qualitative research using data that has already been collected using traditional means. Buckley et al.'s (2017) call to address grand challenges of the IB environment underlines the importance of pursuing phenomenon-driven research. Our argument is that external shocks within the global environment (such as Covid-19) require adaptations in IB research methodologies away from standardized quantitative methods informed by narrow theories, and toward adopting qualitative phenomenon-driven approaches that lead us to recognize and understand the new and unexpected reality.

\section{ABOUT THE AUTHORS}

Amir Qamar is Assistant Professor in Strategic Management at Birmingham Business School, University of Birmingham. His research interests include investigating multiplier effects within certain supply chains, the employment footprint of MNEs, ambidextrous production processes, $\mathrm{R} \& \mathrm{D}$ initiatives, and productivity levels. Amir is also an Officer of the Academy of International Business (AIB) Research Methods Shared Interest Group (RM-SIG).

John Child is Emeritus Professor of Commerce at the University of Birmingham. His degrees (MA, PhD, ScD) were awarded by the University of Cambridge. In 2006, he was elected a Fellow of the prestigious British Academy [FBA]. He is also a Fellow of the Academy of International Business, the Academy of Management, and the British Academy of Management. He has served as Editor-in-Chief of Organization Studies and Senior Editor of Management and Organization Review. John's publications have over 53,000 Google Scholar citations.

Submitted: November 05, 2020 EST, Accepted: August 11, 2021 EST 


\section{REFERENCES}

Aguzzoli, R., Gardner, E., \& Newburry, W. 2021. Letter from the Editors: Special Forum on "Research Methods in International Business.” AIB Insights, 21(2). https://doi.org/10.46697/001c.24425.

Bird, C. M. 2005. How I Stopped Dreading and Learned to Love Transcription. Qualitative Inquiry, 11(2): 226-248.

Brown, A. D. 2005. Making sense of the collapse of Barings Bank. Human Relations, 58(12): 1579-1604.

Buckley, P. J. 2020. International Business Research and the World Investment Report:"Big Questions" and Grand Challenges. AIB Insights, 20(4): 17987.

Buckley, P. J., Doh, J. P., \& Benischke, M. H. 2017. Towards a renaissance in international business research? Big questions, grand challenges, and the future of IB scholarship. Journal of International Business Studies, 48(9): 1045-1064.

Collinson, S. 2017. The declining relevance and legitimacy of IB scholarship in a world that really needs it. AIB Insights, 17(2): 7-10.

DeHart, M. 2020. Thinking Ethnographically in Pandemic Times. Social Science Research Council. ht tps://items.ssrc.org/covid-19-and-the-social-science s/social-research-and-insecurity/thinking-ethnograp hically-in-pandemic-times.

Delios, A. 2017. The death and rebirth (?) of international business research. Journal of Management Studies, 54(3): 391-397.

Denham, M. A., \& Onwuegbuzie, A. J. 2013. Beyond words: Using nonverbal communication data in research to enhance thick description and interpretation. International Journal of Qualitative Methods, 12(1): 670-696.

Dodds, S., \& Hess, A. C. 2020. Adapting research methodology during COVID-19: Lessons for transformative service research. Journal of Service Management, 32(2): 203-217.

Geisen, E. 2020. Social distancing in market research: Pivoting in-person methodologies. Qualtrics. http s://www.qualtrics.com/blog/social-distancing-marke t-research/.

Huniche, L., \& Sørensen, E. 2019. Phenomenondriven research and systematic research assembling: Methodological conceptualisations for psychology's epistemic projects. Theory \& Psychology, 29(4): $539-558$
Jamieson, L. 2020. COVID 19 and "Big Qual" Research. International Journal of Social Research Methodology. https://ijsrm.org/2020/04/16/covid-1 9-and-big-qual-research/.

Jenner, B. M., \& Myers, K. C. 2019. Intimacy, rapport, and exceptional disclosure: a comparison of inperson and mediated interview contexts. International Journal of Social Research Methodology, 22(2): 165-177.

Jowett, A. 2020. Carrying out Research Under Lockdown: Practical and Ethical Considerations. London School of Economics, Blog. https://blogs.lse.a c.uk/impactofsocialsciences/2020/04/20/carrying-ou t-qualitative-research-underlockdown-practical-andethical-considerations/.

Lobe, B., Morgan, D., \& Hoffman, K. A. 2020. Qualitative data collection in an era of social distancing. International Journal of Qualitative Methods, 19: 1609406920937875.

Marhefka, S., Lockhart, E., \& Turner, D. 2020. Achieve Research Continuity During Social Distancing by Rapidly Implementing Individual and Group Videoconferencing with Participants: Key Considerations, Best Practices, and Protocols. AIDS and Behavior, 1-7. Advance online publication.

Markham, A. 2003. Critical junctures and ethical choices in internet ethnography. In M. Thorseth (Ed.), Applied Ethics in Internet Research: 51-63. Trondheim: Programme for Applied Ethics, Norwegian University of Science and Technology.

Mosca, L. 2014. Methodological Practices in Social Movement Research. In D. D. Porter (Ed.), Methodological Practices in Social Movement Research: 397-417. Oxford: Oxford University Press.

Nielsen, B. B., Welch, C., Chidlow, A., Miller, S. R., Aguzzoli, R., et al. 2020. Fifty years of methodological trends in JIBS: Why future IB research needs more triangulation. Journal of International Business Studies, 51(9): 41267-41020.

Ravitch, S. M. 2020. The Best Laid Plans... Qualitative Research Design During COVID-19. Social Science Space. https://socialsciencespace.com/2020/03/the-b est-laid-plans-qualitative-research-design-during-co vid-19/.

Saunders, M., Lewis, P., \& Thornhill, A. 2019. Research Methods for Business Students (8th ed.). Pearson Education. 
Schwarz, G. M., \& Stensaker, I. G. 2016. Showcasing phenomenon-driven research on organizational change. Journal of Change Management, 16(4): 245-264.

Shaheen, M., \& Pradhan, S. 2019. Sampling in qualitative research. Qualitative techniques for workplace data analysis: 25-51. IGI Global.

Sharma, P., Leung, T. Y., Kingshott, R. P. J., Davcik, N. S., \& Cardinali, S. 2020. Managing uncertainty during a global pandemic: An international business perspective. Journal of Business Research, 116: 188-192.

Sinkovics, R. R., Penz, E., \& Ghauri, P. N. 2008.

Enhancing the trustworthiness of qualitative research in international business. Management International Review, 48(6): 689-714.
Teti, M., Schatz, E., \& Liebenberg, L. 2020. Methods in the Time of COVID-19: The Vital Role of Qualitative Inquiries. International Journal of Qualitative Methods, 19: 1-5.

Welch, C., \& Piekkari, R. 2017. How should we (not) judge the 'quality' of qualitative research? A reassessment of current evaluative criteria in international business. Journal of World Business, 52(5): 714-725.

Wood, E. J. 2020. Resuming Field Research in Pandemic Times. Social Science Research Council. ht tps://items.ssrc.org/covid-19-and-the-social-science s/social-research-and-insecurity/resuming-field-rese arch-in-pandemic-times/.

World Economic Forum. 2020. The COVID-19 economy: does it mean the end of globalization? http s://www.weforum.org/agenda/2020/05/globalisation-c ovid19-gdp-drop-2008-financial-crisis. 